LUNG CANCER

\title{
Sequential photodynamic therapy (PDT) and high dose brachytherapy for endobronchial tumour control in patients with limited bronchogenic carcinoma
}

\author{
L Freitag, A Ernst, M Thomas, R Prenzel, B Wahlers, H-N Macha
}

Thorax 2004;59:790-793. doi: 10.1136/thx.2003.013599

See end of article for authors' affiliations

Correspondence to: Dr A Ernst, Director, Interventional

Pulmonology, Pulmonary and Critical Care Division, Beth Israel Deaconess Medical Center, Harvard Medical School, 1 Deaconess Road, Boston, MA 02115, USA; aernst@ caregroup.harvard.edu

Received 29 July 2003

Accepted 29 April 2004

\begin{abstract}
Background: Bulky endobronchial tumours in patients with lung cancer are difficult to treat. Brachytherapy and photodynamic therapy (PDT) are variably effective, and the combination of these treatments is not often recommended. However, cell culture studies and animal studies indicate a possible synergistic effect of combining PDT with ionising radiation. We assessed the safety and effectiveness of combined brachytherapy and PDT in patients with bulky endobronchial lung cancer.

Methods: Patients with histologically proven non-small cell bronchogenic carcinoma and bulky endobronchial tumours were treated using a combination of PDT (Photofrin, $2 \mathrm{mg} / \mathrm{kg}$ ) and brachytherapy. Six weeks after PDT, brachytherapy was applied with five fractions of $4 \mathrm{~Gy}$ at weekly intervals. Follow up was performed with standard and autofluorescence bronchoscopy and tissue biopsies every 3 months.

Results: Thirty two patients were treated. Tumours were extensive with lengths ranging from 10 to $60 \mathrm{~mm}$ along the bronchus and estimated volumes ranging from 40 to $3500 \mathrm{~mm}^{3}$. At a mean follow up of 24 months, 26 patients were free of residual tumour and local recurrence. The remaining patients received a second treatment with PDT, brachytherapy, Nd:YAG laser coagulation, or external beam radiation. Distant metastases (lung, lymph node) developed in two of the six patients. Currently, all 32 patients are well. There is no evidence of residual or local recurrent endobronchial cancer in 28 patients and none had severe complications.

Conclusion: The combination of PDT and brachytherapy for treating patients with lung cancer and extensive endobronchial tumour is safe and, in this study, had excellent therapeutic efficacy.
\end{abstract}

B ronchogenic carcinoma is the most common cancer in the United States and Europe. Many patients suffer from marked endobronchial obstruction, either as a presenting symptom or as a recurrence of their malignancy. If the tumours are inoperable, various palliative treatments are usually pursued. Local treatment options are Nd:YAG laser coagulation, cryotherapy, electrocautery, brachytherapy, and photodynamic therapy (PDT). ${ }^{1} \mathrm{Nd}$ :YAG laser resection is the most common method of clearing the airways from exophytic bulky tumours. Photodynamic therapy has emerged as an alternative, with a slower but longer lasting effect. ${ }^{23}$ Its use is considered to be limited to superficial tumours with limited mass and extension. ${ }^{4}$ Intramural and peribronchial tumour growth can be managed by brachytherapy. In two studies we have reported prolonged survival with endobronchial high dose brachytherapy ${ }^{5}$ and good responses to PDT in cases of postoperative cancer recurrence. ${ }^{6}$ We postulated that combining PDT and brachytherapy could improve local tumour control and survival in patients with bulky endobronchial tumours. At the same time, we aimed to assess the safety of combining these treatments.

\section{METHODS}

\section{Patients}

Patients with technically inoperable primary bronchogenic carcinoma and patients with recurrent lung cancer in the airways were eligible for inclusion. Tumours had to be limited to the airways, without evidence of other chest or metastatic disease; otherwise, external beam radiation or chemotherapy would have been pursued. Primary radiation therapy of the airways is not uniformly successful, and therefore we believed that offering alternative therapeutic approaches to an individual patient, such as the one proposed in this study, was ethical. The Institutional Review Board approved the study, and written informed patient consent was obtained in all cases. Patients were followed prospectively to assess the feasibility and results of this approach.

\section{Evaluation}

After routine clinical tests including CT scans, all patients underwent standard bronchoscopy with conventional white light and autofluorescence examination. Biopsy specimens were taken from the tumour and sites proximal and distal to the neoplasm to confirm the diagnosis and tumour margins histologically. Tumour extensions were noted as visible length, width, and height over the bronchial surface level. Tumour volume was estimated as the cubic product of these three values.

\section{Photodynamic therapy}

Photofrin (QLT Pharmaceuticals, Susteren, The Netherlands, or Ipsen Pharma, Ettlingen, Germany) was injected intravenously at a dose of $2 \mathrm{mg} / \mathrm{kg}$ body weight. Patients were instructed to avoid exposure to direct sunlight for 4-6 weeks. Bronchoscopic examination with light activation of the drug was performed 48 hours after injection.

Red light was generated with an argon pumped dye laser (Lambda Plus, Coherent, Palo Alto) or a diode laser (Zeiss, Jena, Germany) adjusted to $630 \mathrm{~nm}$. Optical fibres $(400 \mu \mathrm{m})$ with cylindrical diffusers ranging from 1 to $3 \mathrm{~cm}$ long or microlens fibres were used to debulk the tumours. Tumour tissue was either impaled with the diffuser fibre for interstitial illumination or irradiated on the surface with the help of microlens fibres. Red light was applied at $200 \mathrm{~J} /$ $\mathrm{cm}$ for interstitial treatment or at $100 \mathrm{~J} / \mathrm{cm}^{2}$ for surface treatment. Forty eight hours after the first illumination 
Table 1 Demographic and clinical characteristics of 32 patients with limited bronchogenic carcinoma treated with sequential photodynamic therapy (PDT) and high dose brachytherapy

\begin{tabular}{|c|c|c|c|c|c|c|c|c|c|}
\hline \multirow[b]{2}{*}{ No } & \multirow[b]{2}{*}{ Age (years) } & \multirow[b]{2}{*}{ Sex } & \multirow[b]{2}{*}{ Histology } & \multirow[b]{2}{*}{ Tumour localisation } & \multirow[b]{2}{*}{ Indication for PDT } & \multicolumn{4}{|c|}{ Tumour dimensions } \\
\hline & & & & & & $\begin{array}{l}\text { Length } \\
(\mathrm{mm})\end{array}$ & $\begin{array}{l}\text { Width } \\
(\mathrm{mm})\end{array}$ & $\begin{array}{l}\text { Depth } \\
\text { (mm) }\end{array}$ & $\begin{array}{l}\text { Volume } \\
\left(\mathrm{mm}^{3}\right)\end{array}$ \\
\hline 1 & 70 & $M$ & $\mathrm{sq}$ & rulb & Postop & 10 & 10 & 2 & 200 \\
\hline 2 & 68 & $M$ & sq & lulb & Postop & 35 & 20 & 5 & 3500 \\
\hline 3 & 66 & $M$ & sq & tra, rulb & Emphysema & 30 & 5 & 2 & 300 \\
\hline 4 & 49 & $\mathrm{~F}$ & adcy & bri, lulb & Postop & 15 & 10 & 3 & 450 \\
\hline 5 & 64 & $M$ & sq & rulb & Postop & 20 & 10 & 3 & 600 \\
\hline 6 & 65 & $M$ & sq & lulb, Illb & Card & 15 & 15 & 3 & 675 \\
\hline 7 & 65 & $M$ & sq & rulb & Postop & 10 & 2 & 2 & 40 \\
\hline 8 & 67 & $M$ & sq & $\mathrm{rmb}$ & Card & 10 & 10 & 3 & 300 \\
\hline 9 & 68 & $M$ & sq & Illb & Postop & 10 & 10 & 3 & 300 \\
\hline 10 & 71 & $M$ & sq & lulb, IIlb & Card & 15 & 15 & 3 & 675 \\
\hline 11 & 62 & $M$ & sq & carina & Emphysema & 10 & 10 & 3 & 300 \\
\hline 12 & 80 & $M$ & sq & bri & Card & 20 & 15 & 3 & 900 \\
\hline 13 & 81 & $M$ & $\mathrm{ad} / \mathrm{sq}$ & tra, rulb & Card & 15 & 15 & 2 & 450 \\
\hline 14 & 68 & $M$ & $\mathrm{sq}$ & tra, stump & Postop & 15 & 10 & 3 & 450 \\
\hline 15 & 61 & $M$ & sq & rmb, rulb & Card & 15 & 15 & 3 & 675 \\
\hline 16 & 55 & $\mathrm{~F}$ & sq & L main, IIlb & Emphysema & 50 & 20 & 3 & 3000 \\
\hline 17 & 66 & $M$ & sq & lllb & Card & 50 & 6 & 2 & 600 \\
\hline 18 & 52 & $M$ & sq & rllb & Emphysema & 20 & 5 & 3 & 150 \\
\hline 19 & 59 & $M$ & sq & $\mathrm{rllb}$ & Card & 25 & 10 & 3 & 750 \\
\hline 20 & 62 & $M$ & $s q$ & lllb & Postop & 30 & 10 & 3 & 300 \\
\hline 21 & 57 & $M$ & sq & rulb & Postop & 20 & 5 & 3 & 150 \\
\hline 22 & 63 & $\mathrm{~F}$ & sq & tra, bri & Postop & 30 & 10 & 5 & 1500 \\
\hline 23 & 69 & $\mathrm{~F}$ & sq & tra & Card & 60 & 10 & 4 & 2400 \\
\hline 24 & 62 & $M$ & sq & rllb & Emphysema & 20 & 5 & 4 & 400 \\
\hline 25 & 76 & $M$ & sq & rulb & Postop & 20 & 5 & 3 & 300 \\
\hline 26 & 68 & $M$ & sq & tra & Postop & 40 & 8 & 3 & 960 \\
\hline 27 & 66 & $M$ & sq & lulb & Postop & 5 & 5 & 3 & 150 \\
\hline 28 & 78 & $M$ & sq & rul, lul carina & Postop & 30 & 10 & 3 & 900 \\
\hline 29 & 64 & $M$ & sq & tra & Postop & 50 & 10 & 2 & 1000 \\
\hline 30 & 51 & $M$ & sq & rulb & Postop & 20 & 5 & 2 & 100 \\
\hline 31 & 69 & $M$ & sq & lulb & Card & 20 & 5 & 3 & 300 \\
\hline 32 & 70 & $M$ & sq & rulb & Postop & 15 & 10 & 2 & 300 \\
\hline
\end{tabular}

another bronchoscopic examination was performed for debridement and re-evaluation. If indicated, another illumination with $100 \mathrm{~J} / \mathrm{cm}$ (or $50 \mathrm{~J} / \mathrm{cm}^{2}$ ) was applied. Therapeutic bronchoscopies were performed two or three times, depending on the tissue reaction.

\section{Brachytherapy}

Biopsy specimens were taken from the treated sites during bronchoscopy 5-6 weeks after PDT and high dose brachytherapy with iridium-192 was administered. A catheter ( $4 \mathrm{~mm}$ outside diameter) was introduced using the Seldinger technique with flexible bronchoscopy under local anaesthesia. If a carina was involved, two catheters were placed. A dose of $4 \mathrm{~Gy}$, calculated at a distance of $10 \mathrm{~mm}$ from the source axis, was applied. Brachytherapy was repeated five times at weekly intervals until a total dose of $20 \mathrm{~Gy}$ had been administered.

\section{Follow up}

Follow up bronchoscopic examinations were performed every 3 months. Biopsy specimens of the treatment areas were examined by the same pathologist who examined the initial specimens. If tumour recurrence was noted, patients received additional local treatment.

\section{Outcomes}

Outcomes were the presence or absence of tumour as indicated by bronchoscopic inspection and histological analysis.

\section{RESULTS}

Between April 1995 and November 1998, 32 patients with technically inoperable $(n=15)$ or recurrent $(n=17)$ bronchogenic carcinomas were treated sequentially with PDT and brachytherapy (table 1). All tumours were functionally or technically unresectable. The tumours were limited to the bronchial wall and other metastatic disease was not evident.

Complete response was achieved in 24 patients (75\%) after initial PDT, as indicated by negative histological results in multiple biopsy specimens from the original tumour site (table 1). In one patient squamous cell carcinoma cells were still found after brachytherapy; in all other patients the biopsy specimens became negative after brachytherapy. Thus, the combined treatment had a complete histological response rate of $97 \%(31 / 32)$. The remaining patient received additional brachytherapy with $8 \mathrm{~Gy}$. Although the tumour is still present, he is alive and well 37 months after initial treatment.

Cancer recurred in six patients (19\%) at 6, 9, 11, 12, 24, and 26 months after PDT (table 2). Five neoplasms were found at the original site. In one patient recurrence developed $2 \mathrm{~cm}$ distal to the original tumour. Using external beam radiation, brachytherapy, Nd:YAG laser coagulation, or additional PDT, tumours were eradicated in three of these six patients. In one patient pulmonary parenchymal metastasis was found 11 months after PDT, and in another patient lymph node metastasis was detected after 3 months. Both patients were successfully treated with external beam radiation and no tumour cells were found in the bronchus. At present, all 32 
Table 2 Initial and current response of 32 patients with limited bronchogenic carcinoma treated with sequential photodynamic therapy (PDT) and high dose brachytherapy

\begin{tabular}{|c|c|c|c|c|c|c|c|}
\hline \multirow[b]{2}{*}{ No } & \multicolumn{2}{|c|}{ Response to brachytherapy } & \multirow{2}{*}{$\begin{array}{l}\text { Relapse (months } \\
\text { since treatment) }\end{array}$} & \multirow{2}{*}{$\begin{array}{l}\text { Intervention after } \\
\text { relapse }\end{array}$} & \multirow{2}{*}{$\begin{array}{l}\text { Current endoscopic } \\
\text { status }\end{array}$} & \multirow{2}{*}{$\begin{array}{l}\text { Current histological } \\
\text { status of airway }\end{array}$} & \multirow{2}{*}{$\begin{array}{l}\text { Months since } \\
\text { first PDT }\end{array}$} \\
\hline & Endoscopic & Histological & & & & & \\
\hline 1 & Complete & Negative & & & No tumour & Negative & 46 \\
\hline 2 & Complete & Negative & & & No tumour & Negative & 43 \\
\hline 3 & Complete & Negative & 9 & Brachytherapy & No tumour & Positive & 40 \\
\hline 4 & Complete & Negative & & & No tumour & Negative & 39 \\
\hline 5 & Complete & Negative & & & No tumour & Negative & 37 \\
\hline 6 & Complete & Positive & & $\begin{array}{l}\text { Brachytherapy, } \\
\text { YAG laser }\end{array}$ & Visible tumour & Positive & 37 \\
\hline 7 & Complete & Negative & & & No tumour & Negative & 35 \\
\hline 8 & Complete & Negative & & & No tumour & Negative & 34 \\
\hline 9 & Complete & Negative & & & No tumour & Negative & 33 \\
\hline 10 & Complete & Negative & & & No tumour & Negative & 31 \\
\hline 11 & Complete & Negative & 11 & XRT & No tumour & Negative & 29 \\
\hline 12 & Complete & Negative & & & No tumour & Negative & 27 \\
\hline 13 & Complete & Negative & & & No tumour & Negative & 27 \\
\hline 14 & Complete & Negative & 12 & PDT & Visible tumour & Positive & 25 \\
\hline 15 & Complete & Negative & 24 & YAG laser & Suspicious & Positive & 24 \\
\hline 16 & Partial & Negative & 26 & PDT & No tumour & Negative & 23 \\
\hline 17 & Partial & Negative & & & No tumour & Negative & 23 \\
\hline 18 & Complete & Negative & & & No tumour & Negative & 22 \\
\hline 19 & Complete & Negative & & XRT & Pulm metastasis & Negative & 22 \\
\hline 20 & Complete & Negative & & & No tumour & Negative & 22 \\
\hline 21 & Complete & Negative & & & No tumour & Negative & 20 \\
\hline 22 & Complete & Negative & & & No tumour & Negative & 20 \\
\hline 23 & Complete & Negative & & & No tumour & Negative & 19 \\
\hline 24 & Complete & Negative & & & No tumour & Negative & 19 \\
\hline 25 & Complete & Negative & & & No tumour & Negative & 16 \\
\hline 26 & Complete & Negative & & XRT & Lymph node metastasis & Negative & 16 \\
\hline 27 & Complete & Negative & & & No tumour & Negative & 13 \\
\hline 28 & Complete & Negative & & & No tumour & Negative & 10 \\
\hline 29 & Complete & Negative & & & No tumour & Negative & 7 \\
\hline 30 & Complete & Negative & & & No tumour & Negative & 6 \\
\hline 31 & Complete & Negative & & & No tumour & Negative & 3 \\
\hline 32 & Complete & Negative & & & No tumour & Negative & 3 \\
\hline
\end{tabular}

patients are alive and well after a mean follow up period of 24 months (range 3-46).

There were no severe complications such as haemoptysis, fistulas, or post-obstructive pneumonia. As expected, temporary mucosal swelling occurred in most cases. Necrotic tissue and fibrin commonly accumulated during the first week after PDT but were always easily cleared by bronchoscopy. Moderate scarring of the bronchus 2-3 months after treatment was usually observed in the radiated bronchial segment. None of the obstructions was severe enough to require intervention.

The patients were well informed about light protection and none experienced sunburn.

\section{DISCUSSION}

Photodynamic therapy with Photofrin is safe and effective, $^{2-4}$ 6-9 $^{-9}$ but high efficacy has only been found when the tumour is smaller than $10 \mathrm{~mm}$ in diameter. Above this critical size the response rate falls from $98 \%$ to $43 \%{ }^{4}$ Other factors determining the outcome are submucosal invasion and peribronchial extension. ${ }^{10}$ Underestimating the extent of the tumour and undertreatment have been identified as reasons for treatment failure. ${ }^{11}$

Brachytherapy is also a well established method of palliation and works well in combination with Nd:YAG laser photoresection to control local tumour growth. ${ }^{5}{ }^{12}$ It is also effective in eradicating early cancer. ${ }^{13}$

Cell culture studies and animal studies indicate a possible synergistic effect of combining PDT with ionising radiation. ${ }^{14}{ }^{15}$ Both result in tumour cell apoptosis but probably via different pathways. ${ }^{16}$ Other studies combining PDT and external beam radiation do not indicate a higher risk of complications. ${ }^{17} 18$
Theoretically, the order of treatment could be reversed, starting with brachytherapy and applying PDT later. However, ionising radiation affects tissue vascularisation. The impaired perfusion of the tumour might result in a lower uptake of the sensitiser, possibly compromising the effect of PDT.

We treated only patients whose tumours were inoperable, either for technical or functional reasons or because of recurrence after surgery. Also, all of our patients had a substantial tumour burden in the tracheobronchial tree. The prognosis for these patients is poor. The results in our study were surprisingly good, with a response rate of $97 \%$. All patients are alive after a mean of 24 months, and the combined treatment failed to eradicate the tumour in only one patient. Relapse occurred at the treated site in five patients, and most of these tumours were successfully treated locally. Also encouraging is the fact that no serious side effects were observed during this aggressive treatment protocol.

Our main interest in this descriptive study was to acquire initial data regarding the feasibility and efficacy of this regimen. As a result, we did not use a randomised trial design. However, our results are extremely encouraging for these difficult to treat patients and we believe that further controlled trials of this treatment regimen are warranted.

We conclude that, in this carefully selected patient population, aggressive combined treatment with PDT and brachytherapy is safe and efficacious in achieving local tumour control.

\section{Authors' affiliations}

L Freitag, M Thomas, R Prenzel, H-N Macha, Department of Pulmonary Medicine, Lungenklinik Hemer, Germany 
B Wahlers, Department of Radiology, Lungenklinik Hemer, Germany A Ernst, Interventional Pulmonology, Beth Israel Deaconess Medical Center, Harvard Medical School, Boston, MA, USA

\section{REFERENCES}

1 Cortese DA, Edell ES. Role of phototherapy, laser therapy, brachytherapy, and prosthetic stents in the management of lung cancer. Clin Chest Med 1993;14:149-59.

2 Vincent RG, Dougherty TJ, Rao U, et al. Photoradiation therapy in advanced carcinoma of the trachea and bronchus. Chest 1984;85:29-33.

3 Moghissi K, Dixon K, Parsons RJ. A controlled trial of Nd-YAG laser vs photodynamic therapy for advanced malignant bronchial obstruction. Lasers Med Sci 1993;8:269-73.

4 Furuse $\mathrm{K}$, Fukuoka $\mathrm{M}$, Kato $\mathrm{H}$, et al. A prospective phase II study on photodynamic therapy with Photofrin II for centrally located early-stage lung cancer. J Clin Oncol 1993;11:1852-7.

5 Macha HN, Freitag L. The role of brachytherapy in the treatment and control of central bronchial carcinoma. Monaldi Arch Chest Dis 1996:51:325-8.

6 Freitag L, Korupp A, Itzigehl I, et al. Experience with laser induced fluorescence diagnostic and photodynamic therapy in a multimodal therapeutic concept for operated, recurrent bronchial cancer. Pneumologie 1996;50:693-9.

7 McCaughan JS, Williams TE. Photodynamic therapy for endobronchial malignant disease: a prospective fourteen-year study. J Thorac Cardiovasc Surg 1997;114:940-6.

8 Edell ES, Cortese DA. Photodynamic therapy in the management of early superficial squamous cell carcinoma as an alternative to surgical resection. Chest 1992;102:1319-22.
9 Cortese DA, Edell ES, Kinsey JH. Photodynamic therapy for early stage squamous cell carcinoma of the lung. Mayo Clin Proc 1997;72:595-602.

10 Lam S, Müller NL, Miller RR, et al. Predicting the response of obstructive endobronchial tumours to photodynamic therapy. Cancer 1986:58:2298-306.

11 Suteddja G, Lam S, LeRiche JC, et al. Response and pattern of failure after photodynamic therapy for intraluminal stage I lung cancer. J Bronchol 1994; 1:295-8.

12 Tredaniel J, Hennequin C, Zalcman G, et al. Prolonged survival after highdose rate endobronchial radiation for malignant airway obstruction. Chest 1994; 105:767-72

13 Perol M, Caliandro R, Pommier P, et al. Curative irradiation of limited endobronchial carcinomas with high-dose rate brachytherapy. Chest 1997:111:1417-23.

14 Dobler-Girdziunaite D, Burkard W, Haller U, et al. Combined treatment of breast carcinoma cells in vitro by photodynamic therapy and ionizing radiation. Strahlenther Onkol 1995;171:622-9.

15 Biel MA, Kim T, Trump MJ. Effect of radiation therapy and Photofrin on tissue response in a rat model. Lasers Surg Med 1993;13:672-6.

16 He XY, Sikes RA, Thomsen S, et al. Photodynamic therapy with photofrin II induces programmed cell death in carcinoma cell lines. Photochem Photobiol 1994;59:468-73.

17 Lam S, Kostashuk ED, Coy EP. A randomized comparative study of the safety and efficacy of photodynamic therapy using Photofrin II combined with palliative radiotherapy versus palliative radiotherapy alone in patients with inoperable obstructive bronchogenic carcinoma. Photochem Photobiol 1987;46:893-7.

18 Imamura S, Kusunoki Y, Takifuji N, et al. Phtodynamic therapy and/or external beam radiation therapy for roentgenologically occult lung cancer. Cancer 1994;73:1608-14.

\section{LUNG ALERT}

\section{Disease progression in COPD correlates with airway remodelling and inflammatory responses}

$\Delta$ Hogg JC, Chu F, Utokaparch S, et al. The nature of small-airway obstruction in chronic obstructive pulmonary disease. $N$ Engl J Med 2004;350:2645-53.

$\mathrm{n}$ this study the lung tissue obtained from surgical resection in 159 patients was examined to correlate pathological findings in the small airways with the severity of COPD using the GOLD classification. The percentage of airways containing polymorphonuclear neutrophils, macrophages, CD4 cells, CD8 cells, B cells, and lymphoid follicles increased with disease progression. The volume of $\mathrm{B}$ cells and CD8 cells also increased with increasing severity of COPD. The progression of COPD through GOLD stages 0-4 was most strongly associated with thickening of the airway wall and each of its components. This is a reflection of the repair or remodelling process within the lung. Disease progression was also associated with the degree of inflammatory response and occurrence of lymphoid follicles in the airway wall, and the presence of mucous exudates within the airway lumen.

This study shows that the adaptive immune response may play a key role in the persistent inflammation associated with COPD. This, and other factors such as infection, are likely to lead to changes in the airway wall that contribute to the small airways obstruction in COPD.

P Ruparelia Clinical Fellow, Addenbrooke's Hospital, Cambridge, UK; pr272@cam.ac.uk 